\title{
Cerebellar medulloblastomata in adults: review of 18 cases
}

\author{
JOHN MILES AND Y. S. BHANDARI \\ From the Midland Centre for Neurosurgery and Neurology, Smethwick
}

Up to 1925 the study of malignant tumours of the brain within the posterior fossa was bedevilled by the existing state of nosological disarray. After careful study of the experience till then, Bailey and Cushing (1925) concluded that many of these tumours, particularly those showing a predilection for children, could be grouped according to their presumed cell source and could be called medulloblastomata.

When Cushing (1930) reviewed his series of 61 cerebellar medulloblastomata he found a very high mortality but observed enough amelioration as a result of treatment to enable him to advocate continued and even repeated surgery and radiotherapy. The majority of his cases were children, but there were nine patients more than 18 years of age. The tumours in this older group were all situated laterally in the cerebellar hemispheres but exhibited the same histological appearance as those seen in children, and there appeared no obvious difference in the natural history or response to treatment. More recent series have, however, tended to provide conflicting evidence as to the life expectancy when clinical presentation is delayed beyond childhood (Spitz, Shenkin, and Grant, 1947; Berger, and Elvidge, 1963). In the presence of such uncertainty, prognostication in the individual case must be uncomfortably empirical. It is with this problem in mind that we have reviewed 18 cases of cerebellar medulloblastomata in older patients admitted to the Midland Centre for Neurosurgery and Neurology, between the years 1954 and 1968.

The age above which a patient is classified as adult varies from 12 to 18 years, and when coupled with an uncertainty of prognosis there is suggested a need for grouping by standard decades. We have therefore considered, in detail, all those aged 10 years and over and briefly compared them with those presenting in the first decade of life.

We have attempted to avoid the problem of tumour nomenclature and all medulloblastomata, desmoblastic medulloblastomata, cerebellar sarcomata, and tumours showing mixed features have been included in one group.

\section{MATERIAL AND METHODS}

In this unit, 18 cases of cerebellar medulloblastomata aged 10 years and over, and 29 cases under 10 years of age, were admitted in the period covered by the report. In the older age group of 18 patients there were eight males and 10 females and in the younger group of 29 there were 19 males and 10 females. In the older group the age of the patients ranged from 10 to 39 years; there being 11 in the second decade, two in the third, and five in the fourth decade.

CLINICAL FEATURES Eight patients $(44 \%)$ presented with less than three months' history, six $(33 \%)$ with three to 12 months' history, and four (22\%) presented i with more than 12 months' history. This was comparable $\infty$ with the length of history elicited in patients in the्ㅁ을 younger age group.

The symptoms of headache, vomiting, ataxia, and visuak deterioration were common and often occurred togethero The relative frequency of symptoms is shown in Table 1 Tinnitus, deafness, photophobia, secondary amenorrhoea $\overrightarrow{0}$ confusion, and drop attacks occurred once each and one patient was pregnant at the time of presentation to hospital. These symptoms were essentially similar to those in the younger group. Table 1 also shows the relative frequency of clinical signs in the group of 18 cases.

Evidence of raised intracranial pressure was found as frequently in the older group as in the younger, but ataxia - particularly unilateral incoordination-was more frequent in the older group. Borghi and Chiorino (1964) observed a similar discrepancy, but this could possibly be due to the relative difficulty in eliciting the signs of incoordination in children.

Lower motor neurone cranial nerve palsies were seen relatively frequently in the older group. The seventh nerve was involved in seven cases and the eighth nerve in one. In the younger group unilateral facial weakness was present in five cases, but in all save one of these cases, the tumour was found at operation to be restricted to the midline structures.

TUMOUR SITES The tumours were located in the sites shown in Table 2.

Right and left hemispheres were involved with about equal frequency in each group.

HISTOLOGY The tumour was histologically typical of medulloblastoma in 12 cases out of 18. In three 
TABLE 1

SYMPTOMS AND SIGNS IN 18 CASES OF MEDULLOBLASTOMA IN OLDER GROUP

\begin{tabular}{lc}
\hline & $\begin{array}{c}\text { Cases } \\
\text { (no.) }\end{array}$ \\
\hline Symptoms & \\
Headache & 18 \\
Vomiting & 15 \\
Ataxia & 15 \\
Visual deterioration & 12 \\
Neck pain & 2 \\
Signs & 14 \\
Papilloedema & 12 \\
Nystagmus & \\
Cranial nerve palsies: & 7 \\
7th & 1 \\
8th & 14 \\
Neck stiffness & 5 \\
\hline
\end{tabular}

TABLE 2

LOCATION OF MEDULLOBLASTOMA IN BOTH GROUPS

\begin{tabular}{lccc}
\hline Group & Hemisphere & Midline & $\begin{array}{c}\text { Hemisphere } \\
\text { and midline }\end{array}$ \\
\hline Older & 10 & 4 & 4 \\
Younger & 5 & 22 & 2 \\
\hline
\end{tabular}

cases there was sarcomatous tumour together with medulloblastoma. In the remaining three cases there was additional astrocytomatous tissue and in two of these three also pathological oligodendroglia.

In the younger group of 29 cases, typical medulloblastoma was found in 25 and, in the remaining four, one case showed astroblastic, one neuroblastic, and one ependymomatous features, while the last had both astrocytic and oligodendroglial elements together with medulloblastoma.

TREATMENT Operative removal appeared to be total in four cases, subtotal in eight, and partial in four cases. In all cases it was considered imperative at least to have established a free flow of cerebrospinal fluid from the upper fourth ventricle or aqueduct.

Radiotherapy to the cranium and vertebral column was given as a routine except where the patient's condition was considered irretrievable or when the patient died before treatment could be started. A total dose of $3500 r$ was given over four to six weeks. One patient in the older group died before radiotherapy had been started and seven children did not receive any.

Two patients in the older group have received a second course of radiotherapy. The first had a recurrence that had been confirmed by operation, but in spite of further radiotherapy he died within two years of the original presentation. The second still survives two and a half years after presentation, but with continuing evidence of recurrence. Three patients in the younger group underwent a further course of radiotherapy when there had been evidence of recurrence but none survived for more than two years after their original presentation.
MORTALITY AND SURVIVAL Tables 3 and 4 show the mortality and survival in the older and younger groups.

In the older group one patient died four days after an operation at which only partial removal had been possible. At post-mortem examination a major amount of tumour was found still in the fourth ventricle and there was evidence that death had been due to persisting brain-stem compression.

In the older group $67 \%$ of the patients survived more than one year but the percentage survival steadily reduced with time, so that only two patients survived more than 10 years, both being still alive 11 and 12 years after operation. In the younger group only $33 \%$ of the cases survived more than one year and only one patient is alive more than 10 years after operation.

TABLE 3

MORTALITY AND SURVIVAL IN MEDULLOBLASTOMA PRESENTING AFTER THE AGE OF 10 (18 CASES)

\begin{tabular}{lccc}
\hline & \multicolumn{2}{c}{ Cases } & $\begin{array}{c}\text { Patients still } \\
\text { alive in 1968 (no.) }\end{array}$ \\
\cline { 2 - 3 } & $($ no. $)$ & $(\%)$ & \\
\hline $\begin{array}{l}\text { Operative mortality (within } \\
\text { 6 weeks of operation) }\end{array}$ & 1 & 6 & \\
Years survived more than: & & & \\
1 & 12 & 67 & 5 \\
3 & 5 & 28 & 3 \\
5 & 4 & 22 & 3 \\
10 & 2 & 11 & 2 \\
\hline
\end{tabular}

TABLE 4

MORTALITY AND SURVIVAL IN MEDULLOBLASTOMA PRESENTING BEFORE THE AGE OF 10 (29 CASES)

\begin{tabular}{lrrr}
\hline & \multicolumn{2}{c}{ Cases } & $\begin{array}{c}\text { Patients still } \\
\text { alive in 1968 (no.) }\end{array}$ \\
\cline { 2 - 3 } & $($ no. $)$ & $(\%)$ & \\
\hline $\begin{array}{l}\text { Operative mortality (within } \\
\text { weeks of operation) }\end{array}$ & 3 & 10 & \\
Years survived more than: & 10 & 33 & 4 \\
1 & 4 & 14 & 3 \\
3 & 3 & 10 & 3 \\
5 & 1 & 3 & 1 \\
10 & & & \\
\hline
\end{tabular}

\section{DISCUSSION}

There remains controversy as to the aetiology of medulloblastomata but as yet there is not sufficient evidence for theories other than the traditionalnamely, that medulloblastomata arise from neuroestodermal embryological remnants (Zülch and Wechsler, 1968). Cells similar to those postulated as the source can be readily seen as an external granular layer in the vermis in the roof of the 4th ventricle in normal brains up to the age of 1 year. Above this age they are not normally seen and, while their fate cannot be authoritatively voiced, they are presumed to migrate into the deeper granular 
layer of the cerebellum. Further evidence for a possibly congenital origin is found when the incidence of the tumour is correlated with age when the considerable predilection for the first decade of life is seen. However, if this deduction is valid, it becomes rather difficult to understand the natural history of tumours appearing in later life, especially when presentation may be delayed until the 57th (Borghi and Chiorino, 1964) or 55th year of life (Berger and Elvidge, 1963; Spitz et al., 1947); and even more difficult when, as illustrated in our series, this delay in presentation is in no way associated with a more insidious or prolonged evolution of the clinical syndrome.

Cushing (1930), Alekseeva (1959), and Berger and Elvidge (1963) reviewed their series of medulloblastoma at all ages and found no difference in the clinical course nor in the survival in adults and children. In contrast, Spitz et al. (1947) and Rubenstein and Northfield (1964) found a significant difference in the survival of patients in the two groups. The improved survival in Rubenstein and Northfields' series appeared to be associated with a more lateral position of the tumour in the adults.

Borghi and Chiorino (1964) in his series of 29 medulloblastomata presenting after the age of 15 obtained figures similar to our own-namely, $56.6 \%$ survived more than one year, $21.7 \%$ more than three years, and $13 \%$ more than four years. Against his figures, of course, must be considered those for children alone, and even here there appears to be no conformity. Tice (1962) in his series of 22 children, found $23 \%$ survived more than seven years with four cases still alive eleven and a half, eleven, nine, and eight years after operation and radiotherapy. Pearson (1964) observed a $38 \%$ five year survival, while Spitz et al. (1947) had no survivors after three years in a series of 67 children.

It is because of these variations that we found it necessary, in attempting to assess the survival of older patients, to compare them with younger patients subjected to the same clinical care, investigation, and treatment. The result reveals a clearly improved prospect for the older patient with double the percentage survival for each period studied up to 10 years.

FACTORS ASSOCIATED WITH PROLONGED SURVIVAL Sex The usually quoted ratio of males to females suffering from medulloblastoma is 2 or 3: 1 (Yates, 1964)-the same as is seen in our younger group. A similar ratio was observed in the adult group of Borghi and Chiorino (1964). In our older group males and females occurred with equal frequency, and among the long survivors-for example, more than three years-four out of five were female.
In the younger group, two boys and two girls survived more than three years.

Age The length of survival seemed to have a definite association with a specific age range, in that three year survivors from each group were all to be found between the ages of 6 and 19 years. In the younger group where the mean age at presentation was 5 years, the four patients surviving more than three years had an average age of 8 years. In the older group where the mean age was 20.3 years, the five patients surviving more than three years had an average age of 14 years.

It appears from these correlations with age and sex that there is an increasing prospect of survival for the female patient presenting in the latter part of the first, or in the second decade. This might possibly be related in some way to the hormonal upheavals of puberty but there is no supporting evidence for this. It is interesting to note that our oldest long-surviving patient presented at the age of 19 having developed secondary amenorrhoea 18 months previously. Eight years after operation and radiotherapy she remains well but amenorrhoeic. Another patient presented at the age of 32 years already three months pregnant and survived operation by only two months.

Older patients-for example, those presenting in the fourth decade-did not survive long.

CLINICAL FEATURES Neither specific symptoms nor their duration bore any relationship to the survivapi of patients in either group. Ataxia was more readily recognized in the older patient as was noted by Borghi and Chiorino (1964). We found lower motor neurone cranial nerve palsies to be common with the seventh nerve being affected in seven cases, and the eighth nerve in another. Borghi and Chiorino (1964) also found lower motor neurone cranial nerve palsies with adult medulloblastomata and recorded one seventh nerve, one eighth nerve, three tenth nerve, and three fifth nerve palsies. In neither series did they appear to be associated with an unusual clinical course.

The aetiology of these palsies is uncertain but they may be due to torsional effects on the brainstem as it is displaced by the space occupying tumour. Certainly they need not be evidence for direct infiltration of the nerves or the brain-stem, as we have observed complete recovery from a seventh nerve palsy in our longest surviving adult, and prompt post-operative recovery from deafness in a more recent case. These palsies have, however, not been particularly related to lateral tumours and have been seen in one contralateral and one midline tumour.

TUMOUR SITE Unlike Rubenstein and Northfield 
(1964) we found no correlation between tumour site and survival.

TUMOUR TYPE There was no histological clue to length of survival. In the five older patients surviving more than three years, four appeared histologically to be typical medulloblastomata, while the other one had some astrocytomatous differentiation. Survival was not extraordinary in the five other tumours exhibiting sarcomatous or combined astrocytomatous and oligodendrogliomatous features. In the four long-surviving children, three had histologically typical medulloblastomata, while the other one had some features of astrocytoma and oligodendroglioma. Three medulloblastomata in children with astroblastic, neuroblastic, and ependymomatous features survived badly.

TREATMENT There was no correlation between length of survival and the amount of tumour removed at operation. The initial course of radiotherapy had been standard and no patient from whom radiotherapy had been withheld survived well. Additional radiotherapy was given in some cases when recurrence was suspected but it was not associated with any significant improvement in survival.

\section{CONCLUSION}

Adults suffering from medulloblastomata of the cerebellum survive twice as well as children when treatment consists of operation to decompress the brain-stem and to relieve any obstructive hydrocephalus, together with radiotherapy to the brain and spinal cord.

This increased prospect of survival is not directly related to the age of presentation but appears particularly to be evident in those presenting in the second decade of life, and the same influence is perhaps evident in children in the latter part of the first decade.

Females in this group seem particularly likely to survive, but there is little evidence for an obvious hormonal or pubertal influence.

Presentation is essentially the same in the adult as in the child, and a prolonged history does not denote benignity. Cranial nerve palsies especially affecting the seventh and eighth nerves appear to be a feature of medulloblastomata in the adult.

In the older patient the tumour is likely to be laterally placed, while in the child it is usually midline, but in neither group of patients is there correlation between the position of the tumour and length of survival.
There is no correlation between histological variants of medulloblastoma and survival.

\section{SUMMARY}

A study has been made of patients with medulloblastomata of the cerebellum who have presented to the Midland Centre for Neurosurgery and Neurology between the years 1954-68. Particular reference has been made to the 18 patients presenting when more than 10 years of age.

An increased prospect of survival in this group when compared with 29 patients presenting before the age of 10 has been noted and possible associations with prolonged survival have been sought.

The relatively favourable outlook of this tumour when it presents in the female in the second decade of life (and possibly even in the female in the latter part of the first decade) is noted but otherwise there is little evidence, clinical, operative, or histological, upon which to create an accurate prognosis.

We are indebted to the medical and surgical staff of the Midland Centre for Neurosurgery and Neurology for permission to study patients under their care, to Mr. W. Bond under whose surveillance radiotherapy was conducted, and to Mr. J. M. Small for advice and guidance in the preparation of this report.

\section{REFERENCES}

Alekseeva, V. S. (1959). Medulloblastomatas of the posterior cranial fossa in adults. Vopr. Neirokhir., 6, 30-33. (In Russian.) (1960). Medulloblastomatas of the posterior cranial fossa in adults. Excepta. med. (Amst.), Sect. VIII, 13, 673-674. (English abstract of above.)

Bailey, P., and Cushing, H. (1925). Medulloblastoma cerebelli: a common type of midcerebellar glioma of childhood. Arch. Neurol. (Chic.), 14, 192-223.

Berger, E. C., and Elvidge, A. R. (1963). Medulloblastomatas and cerebellar sarcomas. A clinical survey. J. Neurosurg., 20, 139-144.

Borghi, G., and Chiorino, R. (1964). Medulloblastoma in adults. Clinical observation on a series of 29 cases. Neurochirurgia. (Stuttg.), 7, 8-17.

Cushing, H. (1930). Experience with cerebellar medulloblastomas: a critical review. Acta path. microbiol. scand., 7, 1-86.

Pearson, D. (1964). The role of radiotherapy in the treatment of tumours in children. J. clin. Path., 17, 423-426.

Rubinstein, L. J., and Northfield, D. W. C. (1964). The medulloblastoma and the so-called 'arachnoidal cerebellar sarcoma'. A critical re-examination of a nosological problem. Brain, 87, 379-412.

Spitz, E. B., Shenkin, H. A., and Grant, F. C. (1947). Cerebellar medulloblastomata in adults. Arch. Neurol. (Chic.), 57, 417-422.

Tice, G. M. (1962). Treatment and prognosis of medulloblastoma. J. Amer. med. Ass., 182, 629-631.

Yates, P. O. (1964). Tumours of the central nervous system in children. J. clin. Path., 17, 418-422.

Zülch, K. J., and Wechsler, W. (1968). Pathology and classification of gliomas. In Progress in Neurological Surgery. Vol. 2, p. 31. 1-84. Edited by H. Krayenbühl, P. E. Maspes, and W. H. Sweet. Karger: Basel. 